\title{
Climate Change and human impact in Central and South America over the last 2000 years
}

\author{
J. Ignacio Martínez' , C. González², M. Grosjean ${ }^{3}$ and R. Villalba ${ }^{4}$ \\ LOTRED-SA $3^{\text {rd }}$ Symposium and Training Course, Medellín, Colombia, 7-12 July 2014
}

Within the framework of the PAGES $2 k$ Consortium, which aims to reconstruct large-scale global temperature patterns for the past two millennia, the LOng-Term multi-proxy climate REconstructions and Dynamics in South America (LOTRED-SA) initiative has produced new high-quality datasets for millennial-long quantitative climate reconstructions for South America. Former LOTRED-SA symposia, held in Malargüe (2006) and Valdivia (2010), focused mostly on southern South America. Two special issues edited by Villalba et al. (2009) and Masiokas et al. (2012) featured key datasets from these meetings.

Neukom et al. (2011) demonstrated that significant data gaps exist in (sub)tropical South America preventing a continent-wide paleoclimate reconstruction. Later assessments (PAGES 2k Consortium 2013; Neukom et al. 2014) have shown that pronounced climatic differences existed between South America and the Northern Hemisphere, e.g. the unique warm event in South America during the late $18^{\text {th }}$ to early $19^{\text {th }}$ centuries. Beyond discussing such interhemispheric differences, a big challenge ahead for LOTRED-SA is filling the data gap in the tropics. Available datasets from tree-rings and lake sediments, speleothems, historical documents, vegetation, pollen, and ice cores are mostly from southern South America. Therefore, more data from the tropics, including other proxy archives from marine and lowland areas need to be collected.

South America, extending from the northern tropics to the sub-Antarctic region and incorporating coastal and high Andean settings, offers a wealth of opportunities for studying the paleoclimate of the late Holocene. The LOTRED-SA $3^{\text {rd }}$ Symposium achieved another of its key goals, which was to provide an upto-date synoptic picture of South American climate dynamics. Over 115 researchers from 13 countries currently working on tropical and southern South America presented over a hundred contributions, including new findings from the Neotropics and the adjacent oceanic regions. Although the emphasis of the symposium was on the last $2 \mathrm{ka}$, contributions ranged from the late Holocene to modern climate and included lake and marine sediments, speleothems, tree-rings, and ice core paleoclimate records, in addition to documentary data and model results.

Beyond the climatic aspects of the $2 \mathrm{k}$ initiative, contributions at the symposium also explored how ecosystems responded to and created feedbacks to climate change, and how humans have dealt with the variability. The wide diversity of processes

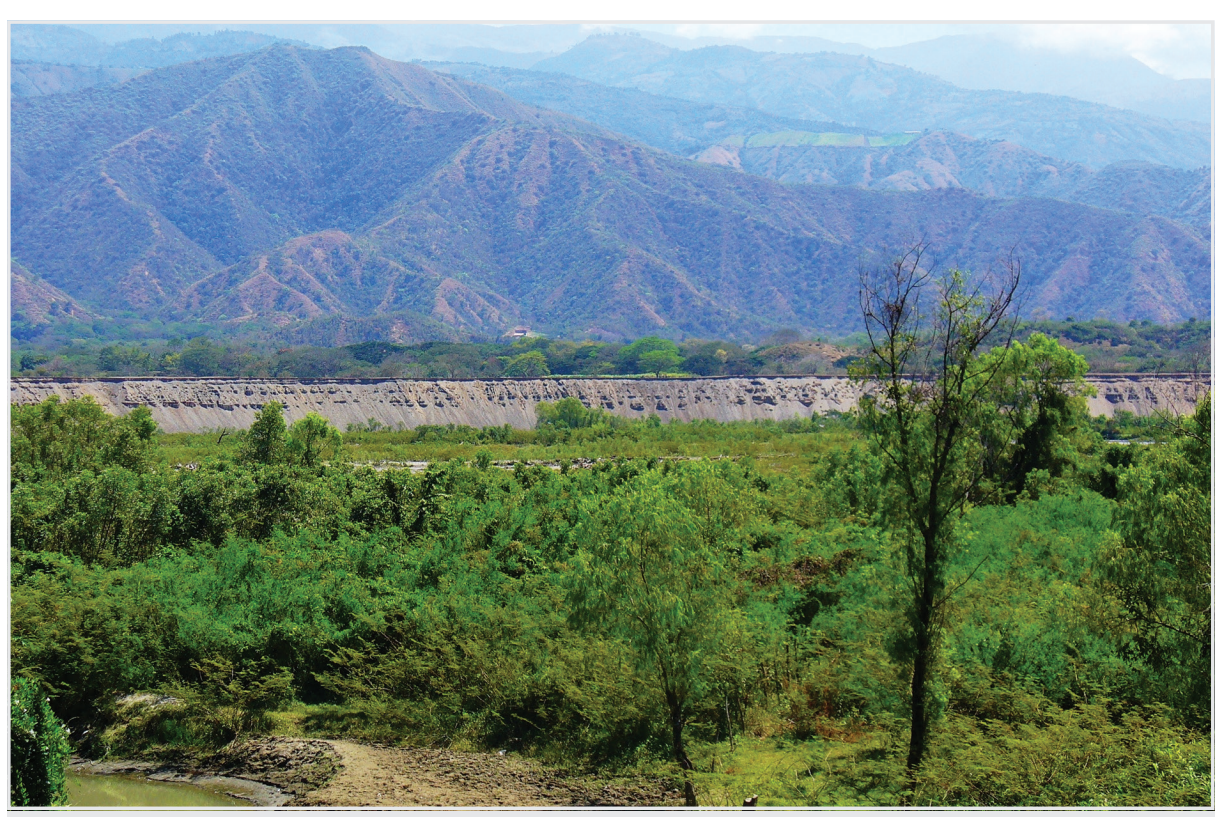

Figure 1: Panoramic view of the San Nicolás terrace in the Santa Fé-Sopetran Basin, northern Colombia. operating in the region include the annual/ decadal migration of the Intertropical Convergence Zone (ITCZ), the dynamics of El Niño-Southern (ENSO), and the multidecadal Pacific (PDO) and Atlantic (AMO) Oscillations. These regional dynamic features seem to explain the Medieval Climate Anomaly, the Little Ice Age, and the current warm period scenarios, all apparently connected through the South American Monsoon System.

An intensive two-day training course for young scientists took place prior to the symposium. It provided training on the building of radiocarbon age models, on the integration of archives, proxies, and sites from the Neotoma Paleoecology Database, and on using R software and Quantum GIS for statistical and spatial analyses. The course, attended by 30 young scientists from 12 countries, was taught by Maarten Blaauw (Queen's University, UK), Alexander CorreaMetrio (UNAM, Mexico), Suzette Flantua (University of Amsterdam, The Netherlands), and Ricardo Villalba (IANIGLA, Argentina).

After the meeting, a field trip took attendants to examine the geomorphology and paleolimnology of the Santa Fé-Sopetrán Basin, where the late Holocene San Nicolás terrace was visited (Fig. 1). This terrace contains a high-resolution succession of laminated sediments whose hydrological multi-decadal frequencies were controlled by the dynamics of the ITCZ.

\section{AFFILIATIONS}

'Dept. Geología, Universidad EAFIT, Medellín, Colombia

${ }^{2}$ Dept. Ciencias Biológicas, Universidad de los Andes, Bogotá, Colombia

${ }^{3}$ Oeschger Centre for Climate Change Research,

University, Bern, Switzerland

${ }^{4}$ Instituto Argentino de Nivología, Glaciología y Ciencias Ambientales IANIGLA, Mendoza, Argentina

\section{CONTACT}

Martin Grosjean: martin.grosjean@oeschger.unibe.ch REFERENCES

Masiokas et al. (2012) Clim Past 8, Spec Iss 42 Neukom R, Gergis J (2011) The Holocene 22: 501-524 Neukom R et al. (2014) Nat Clim Change 4: 362-367 Villalba R et al. (2009) Palaeogeog Palaeoclimatol Palaeoecol 281: 175-376

PAGES 2k Consortium (2013) Nat Geosci 6: 339-346 